\title{
BIM and LCA Integration: A Systematic Literature Review
}

\author{
Tajda Potrč Obrecht ${ }^{1}$ (D), Martin Röck ${ }^{2,3}$, Endrit Hoxha ${ }^{2}$ and Alexander Passer 2,*(D) \\ 1 Slovenian National Building and Civil Engineering Institute, Dimičeva 12, 1000 Ljubljana, Slovenia; \\ tajda.obrecht@zag.si \\ 2 Working Group Sustainable Construction, Graz University of Technology, Waagner-Biro-Straße 100, \\ 8020 Graz, Austria; martin.roeck@tugraz.at (M.R.); endrit.hoxha@tugraz.at (E.H.) \\ 3 Architectural Engineering, Department of Architecture, Faculty of Engineering Science, KU Leuven, \\ Kasteelpark Arenberg 1, 3001 Leuven, Belgium \\ * Correspondence: alexander.passer@tugraz.at
}

Received: 27 May 2020; Accepted: 30 June 2020; Published: 9 July 2020

\begin{abstract}
To foster sustainable development, the environmental impacts of the construction sector need to be reduced substantially. Life cycle assessment (LCA) is the established methodology for the quantification of environmental impacts, and therefore has been increasingly applied to assess the environmental performance of buildings. By coupling LCAs with digital design tools, e.g., building information modeling (BIM), the identification of environmental hotspots and their mitigation is possible during the design process. The objective of the study is to identify the current integration approaches, and determine the pros and cons of the integration process from different viewpoints, namely, technical, informational, organizational and functional issues. Therefore, a comprehensive systematic literature review (SLR) was performed. We identified 60 relevant BIM-LCA case studies and analyzed the applied BIM-LCA workflows in detail. A total of 16 of the reviewed studies applied LCA during the early design stage. These studies used a manual or semiautomatic data exchange between the BIM models and LCA tools. In most cases, contemporary BIM-LCA workflows utilized conventional spreadsheets (e.g., Excel sheets in 16 cases). However, the analysis shows that an automated link between LCA and BIM can be achieved when overcoming the technical, organizational and informational issues discussed in the paper. This could enable the streamlining of LCA applications in design practice, and thus support the necessary improvements in the environmental performance of buildings.
\end{abstract}

Keywords: building information modeling (BIM); life cycle assessment (LCA); systematic literature review (SLR); environmental product declarations (EPD); workflow; bill of quantities (BoQ)

\section{Introduction}

One of the major aims of the Sustainable Development Goals (SDGs) proposed by the United Nations (UN) is to make cities and communities better living places [1]. For this reason, buildings, as the major contributor to climate change, should become sustainable, and consequently their impacts should be reduced. A multidisciplinary approach covering a number of features, such as energy and water savings, minimization of quantity of material use, and emissions control throughout the whole life cycle of the building, is required [2].

Life cycle assessment (LCA) is a potent tool for the calculation of environmental impacts during the entire life cycle of a building. The material and energy flows over the different life cycle phases, namely, the production, construction, use and end-of-life (EoL) stages, are evaluated. Recently, this tool has also been widely applied in the construction sector [2-6]. To perform an LCA of a building, we need 
to gather considerable information regarding the building materials, the building processes, the use phase, the EoL of a building, etc. This step is very demanding and time-consuming [7].

To reduce the efforts connected with performing an LCA study, building information modeling (BIM) can be used. According to the BIM dictionary, BIM is a set of technologies, processes and policies enabling multiple stakeholders to collaboratively design, construct and operate a building or a facility in a virtual space [8]. BIM is modeled using dedicated software tools, and consists of parametric objects that hold information regarding the geometry and other attributes (e.g., functional, semantic and topographic information) of building components [9]. To use BIM to reduce the efforts of LCAs, additional information, with respect to the environmental impacts and other inputs of an LCA study, should be integrated.

The objective of the study is to identify the current integration approaches presented in the literature, and determine the pros and cons of the integration process from different viewpoints. In a narrow sense, we can observe integration as a technical issue of combining different tools. In a broader sense, we have also highlighted the issues of integration from the perspective of the requirements of the LCA methodology; these issues also influence the information needed, and how the process of integration should be organized.

\section{Review Approach}

\subsection{State-of-the-Art}

Several studies have attempted to classify BIM and LCA [7,10-12]. Anton and Diaz [10] presented two possible proposals for the integration of BIM and LCA. The first type involves direct access to BIM model information in order to calculate the environmental performances of buildings. The Industry Foundation Classes (IFC) data sharing format is used for the extraction of information from the BIM model. By eliminating the manual entry of the data, the real-time comparison of project alternatives is enabled. However, this approach has not yet been fully established. The second type requires the inclusion of environmental properties in the BIM objects. The environmental properties would have to be able to develop along with the development of the project, and there are still issues regarding how to include information regarding transportation, maintenance, etc.

Nizam et al. [11] divided the studies into four major types. The first type includes studies that focus on project-based outcomes, but do not provide an integration process description that could be extended to other projects. The second type includes studies that use only BIM as a quantity take-off toll, and export these quantities into other tools. The third type includes studies that are limited to only the cradle-to-site phase. The fourth type of study is identified as not practical enough to be adopted.

Soust-Verdaguer et al. [7] classified the integration of BIM and LCA into three types. The first type is the case where the BIM tool is used during the LCA stage for generating the bill of quantities (BoQ). The second type includes studies in which BIM is used to provide data on the materials, and to calculate the energy demand of the building. The third type includes studies in which BIM and LCA tools are combined in an automatic procedure.

The most comprehensive classification was proposed by Wastiels and Decuypere [12]. These researchers divided BIM-LCA integration into five types. The first type, (1), is the integration of the tools by exporting the BoQ from the BIM environment into other tools. According to their observation, this approach is the most commonly adopted in current practice. The second approach, (2), is the import of surfaces using the IFC format, which are then aligned, by an LCA practitioner, with predefined LCA profiles. The third type, (3), is the approach where information from a BIM tool is further processed in a BIM viewer tool, and is then transferred into dedicated LCA software. The fourth type, (4), is the use of specially developed plug-ins that enable LCA analysis within the BIM tool. The fifth type, (5), is the approach where the LCA information is included in the BIM objects that are used in the BIM model, instead of them being attributed to the building components in a later stage and in separate tools. A great advantage of the last approach is that the information regarding 
the environmental impacts can be analyzed along with the project development. The five different types of integration according to Wastiels and Decuypere are presented in Figure 1. This approach was the basis for the classification of the integration processes identified in the studies.

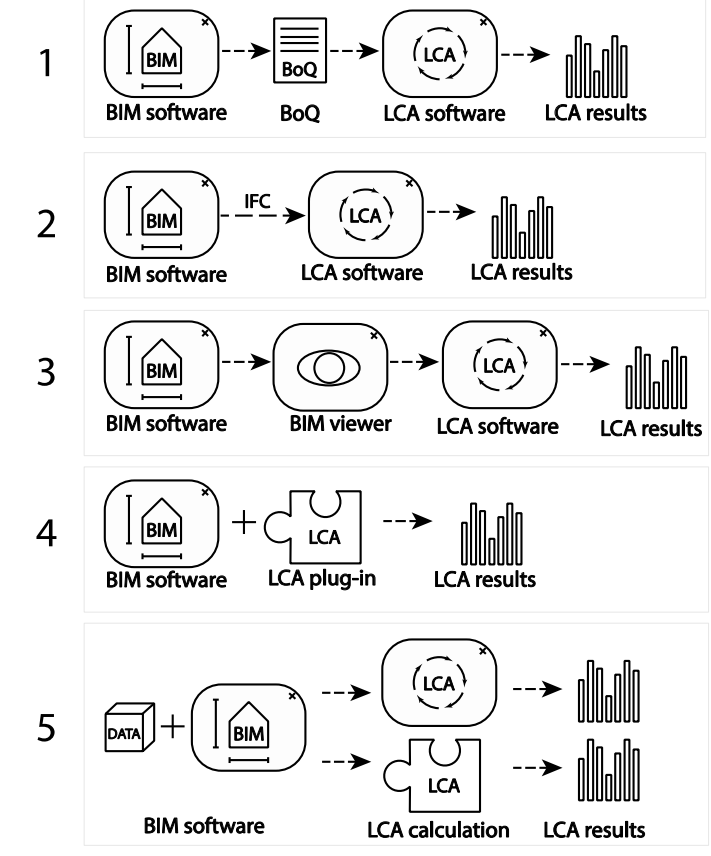

Figure 1. BIM-LCA integration types adapted from Wastiels and Decuypere [12].

\subsection{Materials and Methods}

A systematic literature review (SLR) is a structured procedure for identifying the relevant sources in order to obtain a comprehensive overview of the literature published for a specific research question. Based on the research question, relevant keywords are identified, and the search is performed in the defined databases. The aim of this study is to answer the research question: What current approaches regarding the link/integration of LCA/life cycle costing (LCC) and BIM are presented in the literature? Based on the objective of the study, the keywords identified were "life cycle assessment" or "LCA", and "building information modeling" or "BIM", and the chosen databases were Science Direct, Scopus, Web of Science and Springer. The results were limited to the English language. The search criteria further predicted the exclusion of gray literature (e.g., conference proceedings, Masters and/or doctoral theses, books/chapters), and no time boundaries were set.

The results obtained during the database search were then filtered in three phases: (1) based on the title, (2) based on the abstract, and (3) after reading the full paper. From the final sample of relevant papers, we extracted the data. Additionally, we collected further relevant literature via the "snowball" approach [13], by checking the references of the collected papers and interviewing the experts in this field, as done by [14,15]. The analysis included all the relevant papers published before the end of 2019 .

\subsection{Data Analysis and Research Approach}

In the first phase of the SLR, 271 papers were defined as relevant. The filtering based on the title narrowed the scope to 144 papers. After reading the abstracts, 49 papers remained, and after reading the full papers, the final sample of papers was collected. Additionally, 11 papers were collected with the "snowball approach", which provided the final sample of 60 studies to review. The whole process is presented in Figure 2. All of the selected papers explicitly focus on the integration process of BIM and LCA. The SLR shows the evaluation of the publication years, and selected papers revealed that 
papers dealing with the integration of BIM and LCA are being published with increasing frequency (Figure 3).

What current approaches regarding a link/integration of LCA/LCC and BIM are presented in the literature?

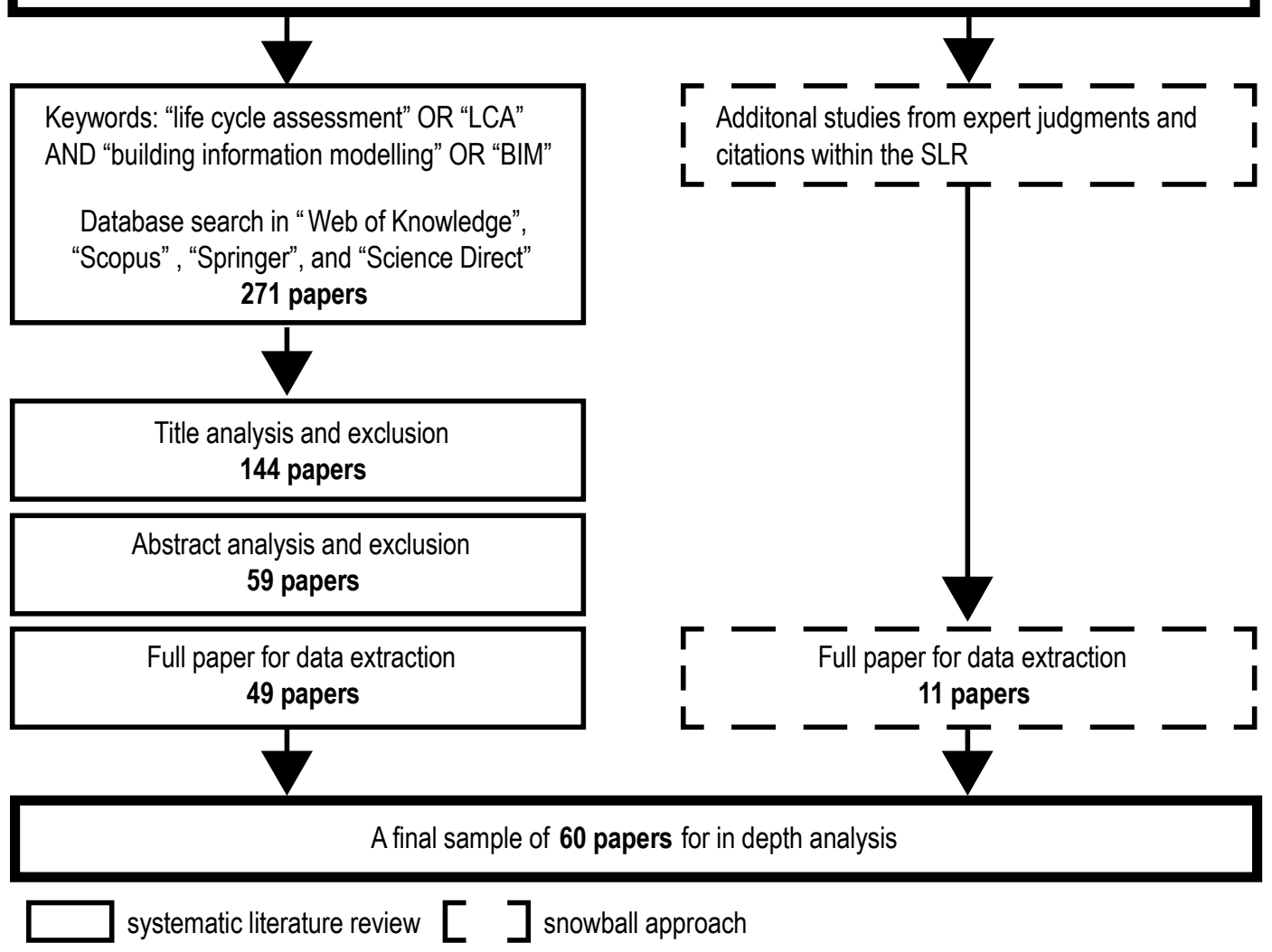

Figure 2. The process of collecting the relevant papers.

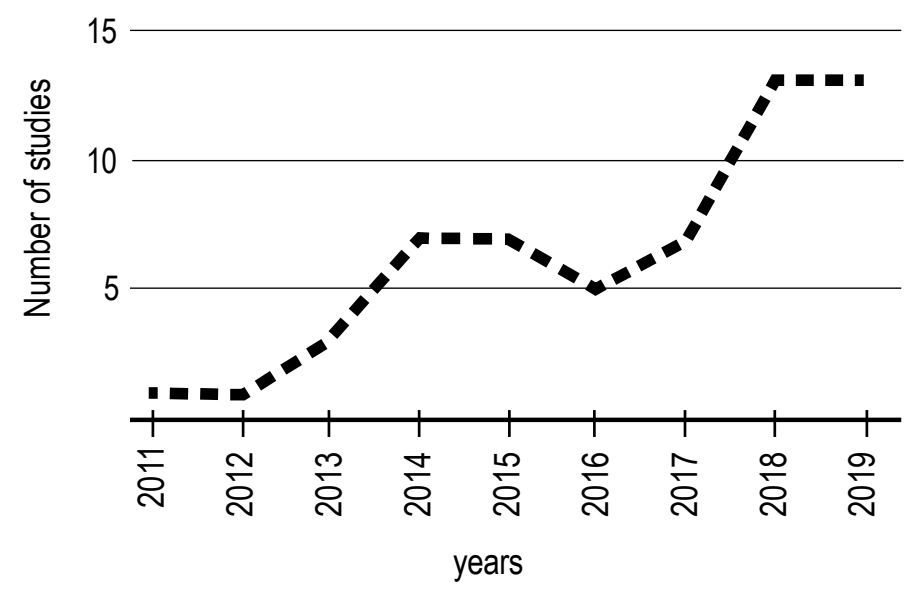

Figure 3. The yearly distribution of the papers identified during the systematic literature review.

Similar to the approach of Volk et al. [9], we observed the issues of LCA and BIM integration from narrow and broad perspectives (Figure 4). From the narrow perspective, the issue of integration can be considered in the sense that BIM is part of the central repository of information that is used in the LCA analysis. The integration process is seen as an exchange of information between two different tools. What information is obtained, and to what degree the process of integration between the BIM 
and LCA tools is automatized, differs between individual cases. The technical issues of BIM and LCA integration are further discussed in Section 3.1.

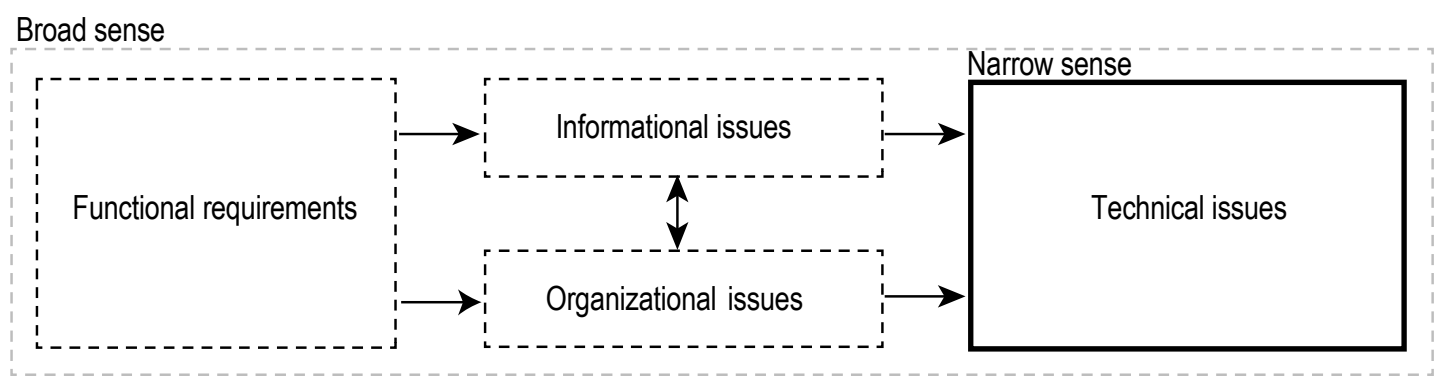

Figure 4. The issues of the BIM-LCA integration.

From the broader perspective of BIM and LCA integration, there are also issues connected to LCA analysis. The analysis is an established methodology, developed independently from BIM. To perform an analysis, certain background knowledge of the process and legislation is required. With this in mind, we have investigated which functional issues the BIM tools face when we try to integrate BIM and LCA simultaneously.

The functionality required by the LCA analysis also determines the information that is required from BIM. The specific information needed to conduct an LCA analysis must adhere to the scope and goals of the study, as well as to the structure of information in the design stage. On the other hand, the structure of the information also enables data exchange between the programs. The informational issues are closely connected to the interoperability of the tools.

Furthermore, the process of integration has to be clearly regulated so that every stakeholder is aware of what kind of information has to be delivered and provided. The organizational issues have to be resolved within the legislation and standards.

\section{Results}

\subsection{Technical Issues}

\subsubsection{Classification of the Integration Process/Interoperability}

The integration process was classified according to the proposal of Wastiels and Decuypere [12], which is described in Section 2.1. The most common link between BIM and LCA tools is the exchange of information via BoQ (BIM-LCA integration type 1), as shown in Figure 5. The second most adopted approach is the use of plug-in tools (BIM-LCA integration type 4). There are also some examples of other workflows, namely, types 2, 3 and 5. Some of the identified studies are review studies, and some of the papers do not present enough data to be able to classify the workflows of the integration.

The data from the BIM model are exported as a schedule (bill of quantity) that contains information regarding the materials used and their quantities (BIM-LCA integration type 1). These data are then imported into an LCA tool manually or automatically, as illustrated in Figure 6. If the import of data into the LCA tool is done manually, which is the most adopted approach, this procedure is very time-consuming, and introduces the risk of errors. Therefore, there are proposals regarding how to automate the exchange process [16-35]. Two studies established a fully automatic exchange of data between BIM and LCA [36,37]. Abanda et al. [36] combined a BIM tool with the .NET framework environment to import the information to Excel. Kumanayake and Luo [37] established an automatic information exchange from BIM to Excel by combining Visual Studio C\# object-oriented programming language with the .NET framework, integrated with a structured query language containing information from the Bath inventory of carbon and energy (ICE) database. On the other hand, several studies have tried to facilitate the integration of BIM and LCA at least to some degree. We have identified 
two general approaches. The first approach tries to integrate diverse additional information into the BIM model [11,38-42]. This integration can be done by adding additional parameters directly to the BIM model $[38,39]$, or by using tools that enable the import of this information, such as Dynamo or similar tools [40-42]. The second approach involves the semiautomated extraction of data from BIM and import to the LCA tools [11,43-45].

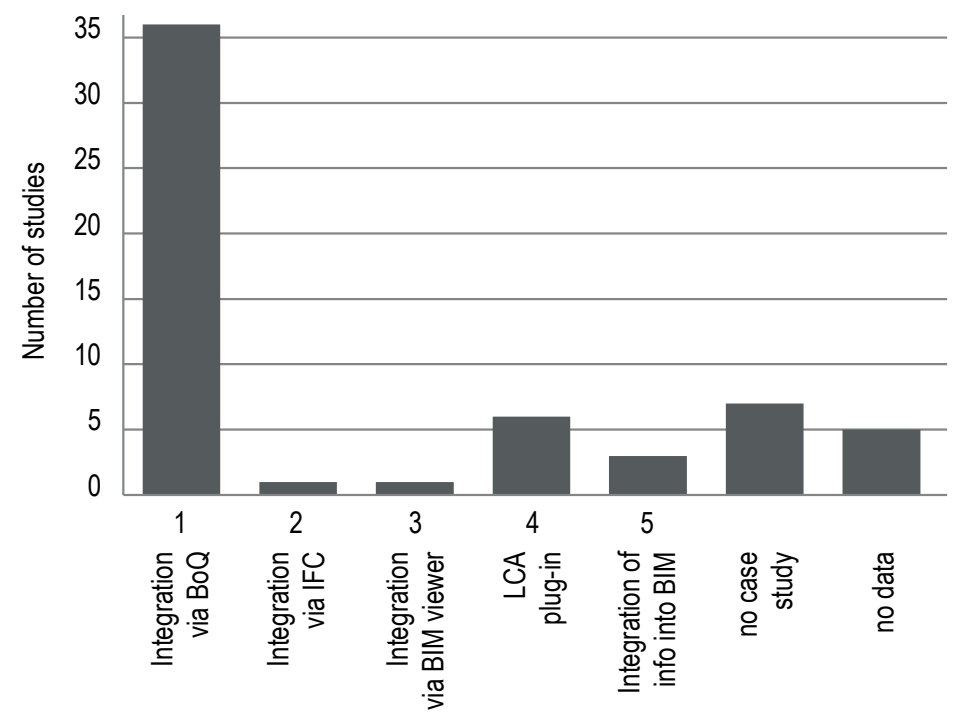

Figure 5. The classification of the workflows in the identified studies.

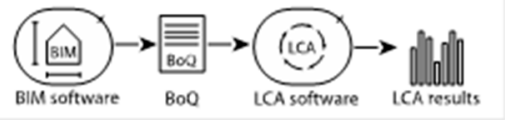

Integration approach by the use of $\mathrm{BoQ}$
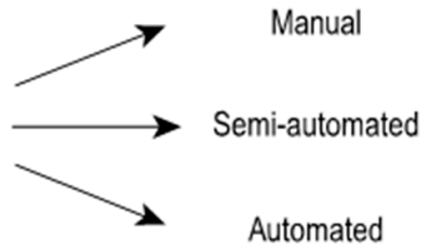

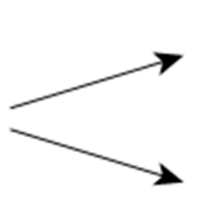

Information integrated

in the BIM model

Improved link between BIM and LCA tools

Figure 6. The division of the bill of quantities integration approach.

The second most adopted approach to integration involves the use of the LCA plug-in tools (BIM-LCA integration type 4). The plug-in enables fast results, but has the limitation that in most cases it uses generic data. Therefore, these tools are often used in the early design stages to identify the most important impacts. Most of the identified studies that used the plug-in approach for the calculation used the Tally tool [46-49]. Tally is a Revit plug-in, and it enables LCA analysis by the use of the Gabi database. If the impacts of the operational phase are also assessed, then Tally can be combined with Green Build Designer, which is also a Revit plug-in. On the other hand, Hollberg and Ruth used the LCA tool as a plug-in and coupled it with the Grasshopper 3D tool within Rhino to optimize the design [50]. Lee et al. developed their own plug-in for Revit that is able to generate results for six impact categories [51]. Jalalei et al. [52] developed a plug-in that serves as a link between BIM, LCA, energy analysis and lighting simulations.

We have identified one study that uses the IFC format for the data exchange between BIM and LCA tools (BIM-LCA integration type 2). Usually, the LCA specialist would link the available LCA profiles in a dedicated LCA software to the building geometry. The advantage of this approach is that a permanent link between the LCA data and the geometry can be established. This can facilitate future interactions of LCA [12]. Kulahcioglu et al. [53] used IFC data to determine the building properties, and although many of the data entries can be facilitated, conversions and integration work still remain to be accomplished; consequently, this approach is considered semiautomatic. A similar approach was taken by Cavalliere et al. [29], but in their approach, there was no exchange with the LCA tool. 
The study of Jalalei et al. [52], wherein a plug-in that serves as a link between the BIM viewer and the LCA tool was developed, was the only identified study in which the BIM viewer was used as an intermediate tool to extract the information for the LCA study (BIM-LCA integration type 3). In this approach, the geometric data are linked with the associated LCA profiles in a BIM viewer tool, and are then sent to dedicated LCA software. The advantage is that the LCA profiles are assigned to the geometry in the 3D environment. The link between the LCA profiles and the geometry is also maintained if a future iteration of LCA is needed [12]. However, we have identified only one example of this in the literature. Wastiels and Decuypere [12] state that this approach is used by the Belgium MMG (environmental profile of building elements) tool.

There are also two studies that coupled the relevant information for the LCA within the BIM environment, and performed the calculation in dedicated LCA software (BIM-LCA integration type 5). The advantage of this approach is that the LCA data are included directly within the BIM model. It is possible to include generic as well as product-specific data. Integration of the environmental data directly with the BIM provides real-time information regarding the environmental impacts, but at the same time bares the risk of creating very big and unresponsive files. The calculation and analysis can be performed with a plug-in, or can be exported to dedicated LCA software. This approach is illustrated by the cases [54-57]. However, the linking of additional information was also performed in other studies where the calculation of the environmental impacts was done with Excel-based tools.

\subsubsection{Automatization of the Integration Process}

Furthermore, we divided the studies based on the degree of automatization of the BIM-LCA integration. The integration can be done manually, which means that the data are transferred by copying and pasting data from one file to another file. In most cases, LCA practitioners are needed to adequately place the data. The second approach is semiautomated. In this approach, the data are exchanged and filled automatically, but for exports and imports, some user interaction is required. The third approach is the so-called "one click" integration. In this approach, the data exchange is fully automated. Figure 7 illustrates the automatization of different BIM-LCA integration types (1-5).

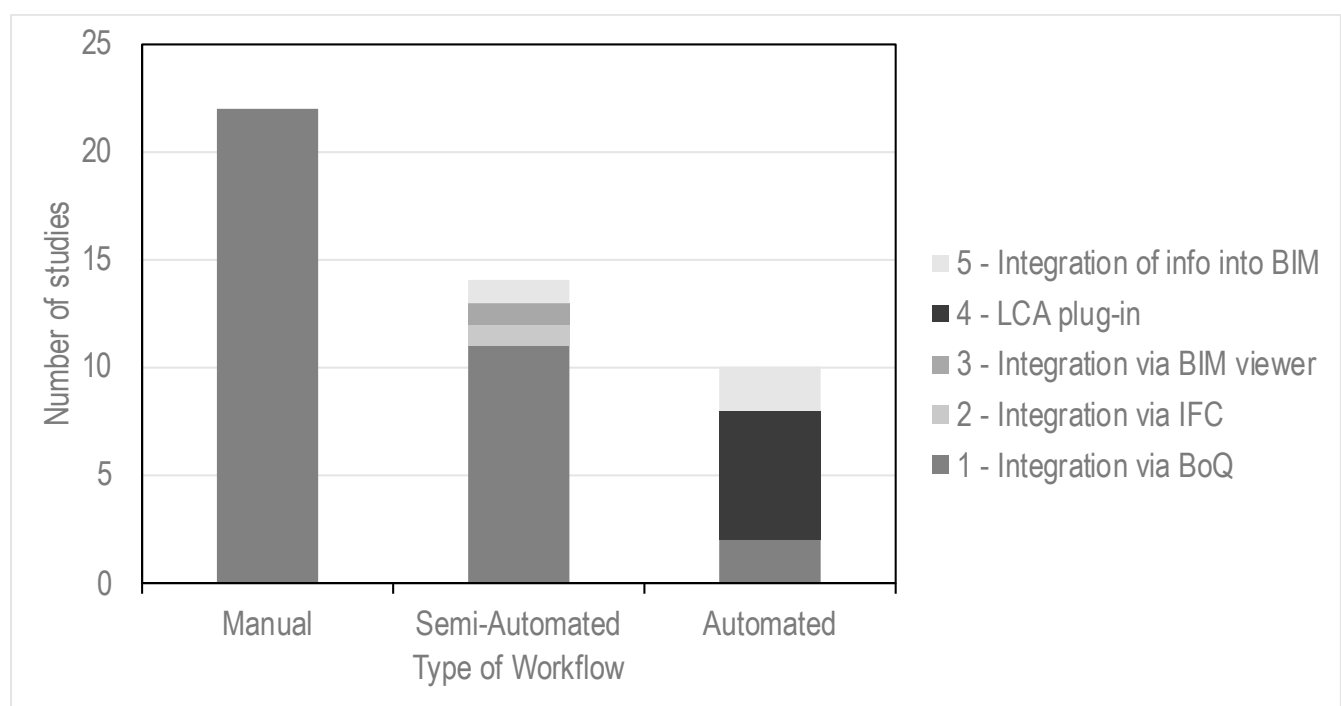

Figure 7. The automation of the link between BIM and LCA.

Most of the data exchange between the BIM and LCA tools is still done manually. The studies mostly use a BIM tool to generate a BoQ. The information collected in the BoQ is then used in a separate tool where the LCA is performed. This approach is very time-consuming, and errors are possible. The semiautomated approach is also commonly used. Some of the information is exported from BIM tools to LCA tools, but this information has to be further processed. In most cases, supplementary 
information is needed that is not available within the BIM environment. The automated approach is most often applied when LCA plug-in tools are used, but there are also some examples of the authors developing scripts from the integration of different tools. The use of a plug-in rapidly generates results, but the tools have certain limitations. For example, sometimes these tools are limited to generic data only, or there is no possibility of adjusting the scenarios within the LCA study. The second approach requires a certain degree of programming skill. The developed scripts enable the coupling of different tools, and can serve as a background development of new LCA tools or plug-ins.

Additionally, we have also identified how the operational energy demand is calculated. We have seen the following approaches to the calculation: (1) a plug-in is developed for the BIM tool, (2) the energy calculation is performed by exporting to an external tool, and (3) the operational energy demand calculation is integrated into BIM. Figure 8 illustrates how the operational energy demand is calculated in the reviewed studies. Additionally, we have also illustrated the BIM-LCA integration type of study.

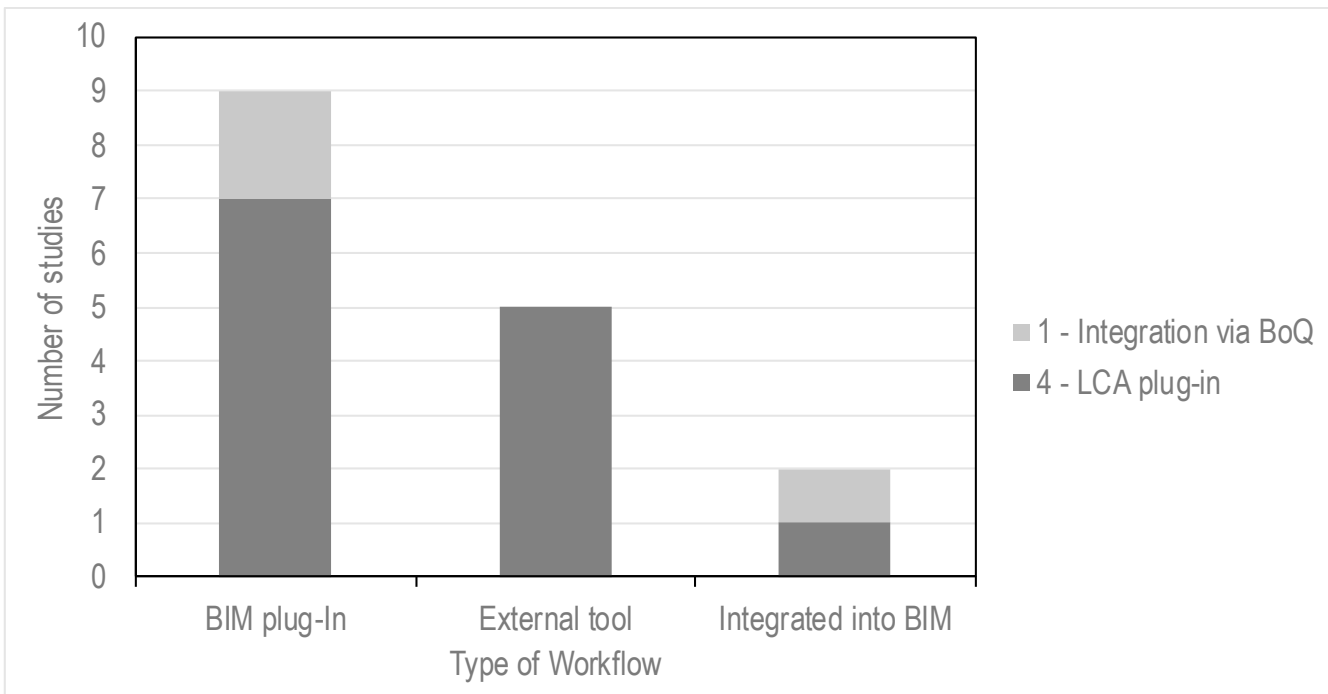

Figure 8. The procedure of the calculation of the operational energy demand (only studies covering the operational energy demand).

\subsubsection{Tools}

The studied cases showed the great variety of tools that are used in the integration process, and the ways in which the information is exchanged between tools. Nevertheless, certain trends in the tools used were identified. The prevailing BIM tool is Revit, which was used in 34 cases. Other BIM tools that were applied were ArchiCAD, Dprofiler, Blender, Sketch UP and Rhinoceros. The BIM model contains mostly information regarding the quantity and quality of the materials. These are important inputs for the calculation of embodied environmental impacts. Additionally, the energy demand of the building has to be calculated in order to obtain inputs for the operational energy demand. The energy calculation (EC) can be performed in an independent tool, as a plug-in to the BIM tool, or it can be integrated into the BIM tool. The applied EC standards of a certain region also influence the choice of which EC tool is used. Another factor is the ease of integration of the EC tools with the BIM tools. Notably, many of the reviewed studies focus on embodied energy, and therefore, no EC tools are used. A wide variety of tools were used, for example, Green Building Studio, which is a plug-in for Revit, and Energy Plus, which is a tool that enables a dynamic energy use calculation. The inputs from different sources were then transferred into tools that enable the calculation of environmental impacts. We are distinguishing between tools that have been specially developed for the LCA, and Excel-based tools [3]. Excel-based tools were applied in 16 cases. The most commonly adopted special LCA calculation tool was Simapro, which was used in eight of the identified cases. Additionally, Tally and Athena were applied in four cases each. The other tools used were Gabi, eLCA, eBalabce, etc., which shows that the integration 
can be done with various tools, especially if the integration is conducted manually. Additionally, we have found that some authors use specific applications that, among other things, offer support when calculating the transport distances of the materials in the construction phase. The possible information flows are illustrated in Figure 9.

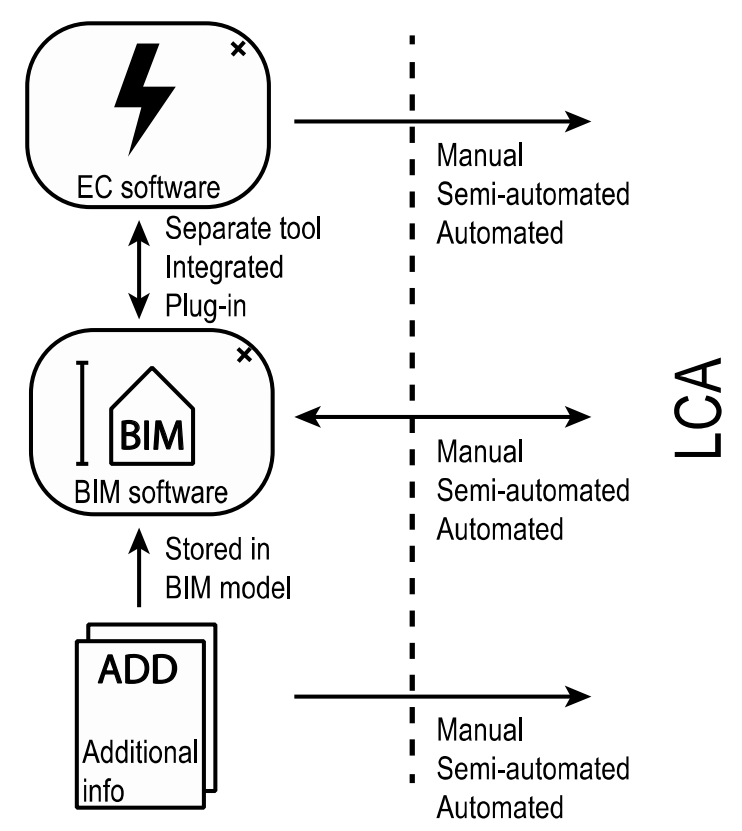

Figure 9. Data exchange between different tools for performing an LCA.

\subsection{Informational Issues}

Each separate stage requires a certain set of information. In Table 1, we have presented the data that are required in the separate life cycle stages (according to EN 15978 [57]), the sources of this information, and whether these data can be acquired from BIM. BIM offers data that can be used to support, extend, calculate or simulate specific data, which can then be integrated again into BIM, or can be used independently $[2,54]$. Some authors have proposed ways to integrate the required information directly into the BIM model $[39,40,54,58]$, but the data that are present in BIM are obtained via additional applications or data sources, such as spreadsheets, existing databases, etc. Nevertheless, there are various possibilities for how this information can be imported into the LCA analysis tool.

The accuracy and quality of the data both depend on the design phase of the projects. There is a lack of consensus with regards to defining the design stages, and the definition differs depending on the country. For example, the design stages according to the Royal Institute of British Architects (RIBA) are divided into eight phases, namely, Strategic Definition, Preparation and Brief, Concept Design, Spatial Coordination, Technical Design, Manufacturing and Construction, Handover and Use [59]. In the Swiss environment, the design process is divided into five phases, namely, Project Planning, Project, Building Permit Application, Tendering and Construction [29]. The use of different design phase definitions makes it difficult to define in which design stage the LCA analysis was conducted. However, 16 out of 60 papers indicate specifically that the LCA is applied in an early design stage, and therefore, there is an even stronger need to integrate the BIM with the LCA tools. Nevertheless, the definition of an early design stage remains unclear.

The design phases are strongly correlated with the level of detail (LOD) of the BIM model. By definition, the LOD defines the geometry as well as the nongeometric attributes provided by the model. To enable the required functionalities, the model has to be modeled with certain accuracy [9]. The LOD of BIM is quantified from LOD 100 to 500, progressively adding information to the model. It is often the case that certain parts of the model are defined at different LODs, because this information is needed for the calculation, or for similar analysis [29]. In the sample of the reviewed papers, only six 
papers defined the LOD $[21,28,29,47,51,60]$. Most of the papers performed the LCA at LOD 300, which was also recommended by Soust-Verdaguer et al. [7]. The study of Cavalierre and others [29] presented a novel approach to developing a continuous LCA calculation throughout the development of the project. The method uses different databases that have different LODs, which corresponds to the LODs of the BIM model.

Table 1. Required data for the LCA of separate LCA stages.

\begin{tabular}{|c|c|c|c|}
\hline Life Cycle Stage & Required Data & Sources & Connection to BIM \\
\hline $\begin{array}{l}\text { Product stage } \\
\text { A1-A3 }\end{array}$ & $\begin{array}{c}\text { Environmental impacts } \\
\text { of materials, } \\
\text { Quantity of materials }\end{array}$ & $\begin{array}{c}\text { Environmental Product } \\
\text { Declaration (EPD), } \\
\text { Databases } \\
\text { BIM }\end{array}$ & Independent or attached \\
\hline $\begin{array}{l}\text { Transport to construction site } \\
\text { A4 }\end{array}$ & $\begin{array}{l}\text { Distances of transport, } \\
\text { Transport means }\end{array}$ & $\begin{array}{c}\text { Spreadsheets } \\
\text { Independent applications } \\
\text { General assumptions }\end{array}$ & Independent \\
\hline $\begin{array}{l}\text { Construction stage } \\
\text { A5 }\end{array}$ & $\begin{array}{l}\text { Energy and materials } \\
\text { needed for construction }\end{array}$ & $\begin{array}{c}\text { Spreadsheets } \\
\text { Independent applications }\end{array}$ & Independent \\
\hline $\begin{array}{c}\text { Use, Maintenance, Repair, } \\
\text { Replacement, Refurbishment } \\
\text { B1-B5 }\end{array}$ & $\begin{array}{c}\text { RSL of the building } \\
\text { materials } \\
\text { EoL scenarios } \\
\text { Maintenance scenarios } \\
\text { Distances of transport, } \\
\text { Transport means }\end{array}$ & $\begin{array}{c}\text { Spreadsheets } \\
\text { Databases } \\
\text { Spreadsheets } \\
\text { Independent applications } \\
\text { General assumptions }\end{array}$ & Independent \\
\hline $\begin{array}{l}\text { Operational Energy } \\
\text { B6 }\end{array}$ & Energy use & $\begin{array}{l}\text { Calculation via plug-in } \\
\text { Export to independent tools }\end{array}$ & $\begin{array}{l}\text { Independent } \\
\text { Plug-in } \\
\text { Embedded }\end{array}$ \\
\hline $\begin{array}{l}\text { Operational Water } \\
\text { B7 }\end{array}$ & Water use & $\begin{array}{l}\text { Spreadsheets } \\
\text { Databases } \\
\text { Assumptions }\end{array}$ & Independent \\
\hline $\begin{array}{l}\text { Deconstruction } \\
\text { C1 }\end{array}$ & $\begin{array}{c}\text { Energy and materials } \\
\text { needed for } \\
\text { deconstruction and } \\
\text { demolition }\end{array}$ & Databases & Independent \\
\hline $\begin{array}{l}\text { Transport to disposal } \\
\text { C2 }\end{array}$ & $\begin{array}{l}\text { Distances of transport, } \\
\text { Transport means }\end{array}$ & $\begin{array}{c}\text { Spreadsheets } \\
\text { Independent applications } \\
\text { General assumptions }\end{array}$ & Independent \\
\hline $\begin{array}{l}\text { Waste processing } \\
\text { C3 }\end{array}$ & $\begin{array}{l}\text { Energy and material } \\
\text { needed for waste } \\
\text { processing }\end{array}$ & $\begin{array}{l}\text { Spreadsheets } \\
\text { Databases } \\
\text { Assumptions }\end{array}$ & Independent \\
\hline $\begin{array}{l}\text { Disposal } \\
\quad \text { C4 }\end{array}$ & $\begin{array}{l}\text { Emission caused by } \\
\text { disposal }\end{array}$ & $\begin{array}{l}\text { Spreadsheets } \\
\text { Databases } \\
\text { Assumptions }\end{array}$ & Independent \\
\hline $\begin{array}{c}\text { Benefits and loads beyond } \\
\text { the system boundary } \\
\text { D }\end{array}$ & $\begin{array}{c}\text { EoL scenarios } \\
\text { Energy and material } \\
\text { needed for waste } \\
\text { processing } \\
\text { Potential benefits }\end{array}$ & $\begin{array}{l}\text { Spreadsheets } \\
\text { Databases } \\
\text { Assumptions }\end{array}$ & Independent \\
\hline
\end{tabular}

Databases and environmental product declarations (EPDs) provide data on the various environmental impacts of building materials, components or elements. Databases can be distinguished based on their scope and completeness; the transparency of data comprises their comprehensiveness as well as their actuality [61]. The information regarding the environmental impact is provided at different levels of data granularity, also correlating with the design stage and the LOD of the project. The use of a data structure and a common naming convention based on an established systemic approach (e.g., Omniclass, Uniclass, Unifromat, etc.) is important when a link between BIM and LCA is established [60]. This structure should provide a common language and a more transparent exchange of information between the different tools and stakeholders. The reviewed studies mostly use data 
on the level of construction materials, while a few also use data at the level of building elements, subelements or raw materials (see Figure 10). Therefore, the majority of the databases that were identified in the reviewed cases (see Figure 10) also contain information at the construction material level. Thus, these databases are suitable for performing the LCA analysis at a later stage, whereat the materials are defined. In later stages, EPDs can also be used. The use of more databases was observed only in cases where the generic databases were combined with EPDs [20,50]. To improve the LCA analysis following the project development, the use of different databases is proposed, since they offer information regarding the accuracy and granularity of the data. This approach was shown in a study by Cavalliere et al., where the progression from the Swiss building database at the beginning of the design, to the Bauteilkatalog for LODs 100-300, and then to the KBOB database for LOD 400, enabled the continuous improvement of the accuracy of the data [29]. Another issue concerns how to structure the databases in order to enable a closer integration with the BIM method. This issue was discussed by Gantner et al. [62] for the database Ökobau.dat. In their study, they offered various proposals regarding how to structure the data to improve the link between LCA and BIM, and also included additional information in the databases (e.g., reference service life, assembling processes of building products, etc.).
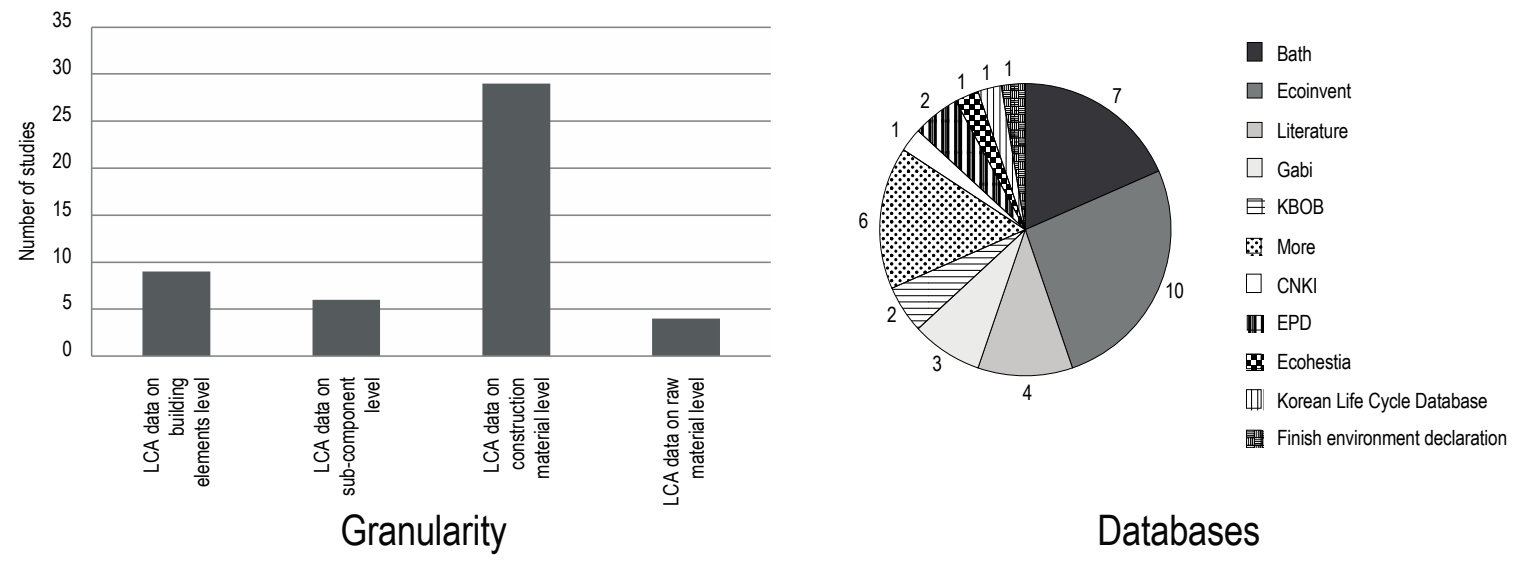

Figure 10. The granularity of the data and the databases used.

\subsection{Functional Requirements for $L C A s$}

The functionalities of BIM required to perform an LCA analysis depend on the scope and goal of the study. These functionalities can be incorporated in the BIM tool, or attached to the BIM tool as independent data, applications, plug-ins, etc.

In the first step of an LCA, we have to define the functional unit of the study. In the review, we distinguish between the functional unit that is clearly declared, and the functional unit defined via an educated guess. In most studies, the chosen unit is the whole building, and the result can be normalized per area. However, some studies have focused on certain building parts, such as curtain walls and building envelopes. There are also many studies that do not present any case studies, and thus do not declare any functional units (Table 2).

Table 2. Functional units.

\begin{tabular}{ccc}
\hline Functional Unit & Declared & Educated Guess \\
\hline Whole building & 4 & 21 \\
Whole building-normalized & 6 & 0 \\
Specific building parts & 9 & 1 \\
Other & & 3 \\
No data & & 15 \\
\hline
\end{tabular}


The scope of the study was based on the definition by the International Energy Agency's Energy in Buildings and Communities Programme (IEA EBC) Annex 72 [63]. Although in most cases the functional unit is the whole building, there is no consensus regarding which parts are assessed when performing an LCA. There have been various attempts to simplify the LCA, and some of them propose that only the building parts that are major contributors to the environmental impacts should be assessed [64]. When the functional unit is the whole building, the major building parts are assessed, but there are deviations in the assessment of the staircases and the central heating and cooling systems (Figure 11). However, the accuracy of the data is dependent on the design stage and the LOD at which the BIM model is generated. We have identified that there are also many studies that focus only on specific building parts.

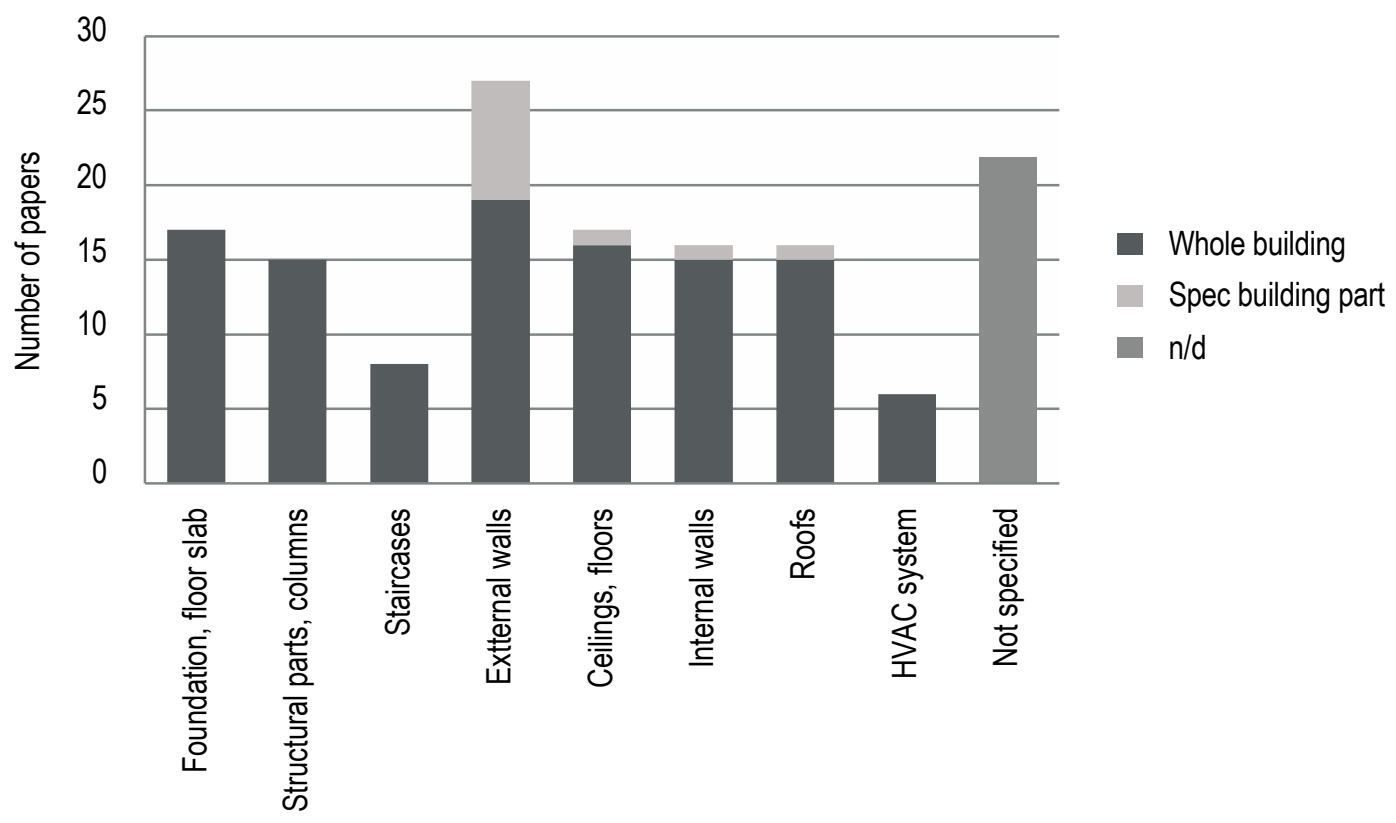

Figure 11. The scope of the selected studies according to the functional unit used.

The life cycle stages assessed in the study determine the required information. The separate stages are divided, according to EN 15978, into the production, construction, use and EoL stages. Additionally, the benefits and loads beyond the life cycle of the building can be assessed. Figure 12 shows that the production phase of the materials is assessed most frequently, while the transport to the construction site and construction work phases are not always included. The phases B1 (use), B3 (repair), B5 (refurbishment) and B7 (operational water use) are addressed only in a few studies. In the EoL stage, most of the reviewed cases assess the disposal of the materials. The benefits and load beyond the reference service life (RSL) of the building were also assessed in a limited number of studies. The sample included 23 papers that only focused on embodied energy, while 26 papers included operational and embodied impacts. The papers that only address operational energy are not included in the scope of our review.

The choice of the relevant impact categories should be aligned with the choice of impact methods. The choice of the impact methods of the reviewed studies is illustrated on the right part of the Figure 13. In a lot of cases no information about the impact method is given. In the case of buildings, the midpoint approach is mostly used, which refers to the environmental impacts connected to climate change, acidification, eutrophication, etc. [2,65]. The reviewed studies mostly address the impact category of global warming potential (GWP). We have also included studies that assess embodied energy, because the integration approaches of BIM and LCA are very similar. Only $23 \%$ of the included studies assess a broader spectrum of the environmental impact categories (Figure 13 left part). This finding 
indicates the potential risk of focusing on the reduction of one category leading to an increase in the impact of other categories.

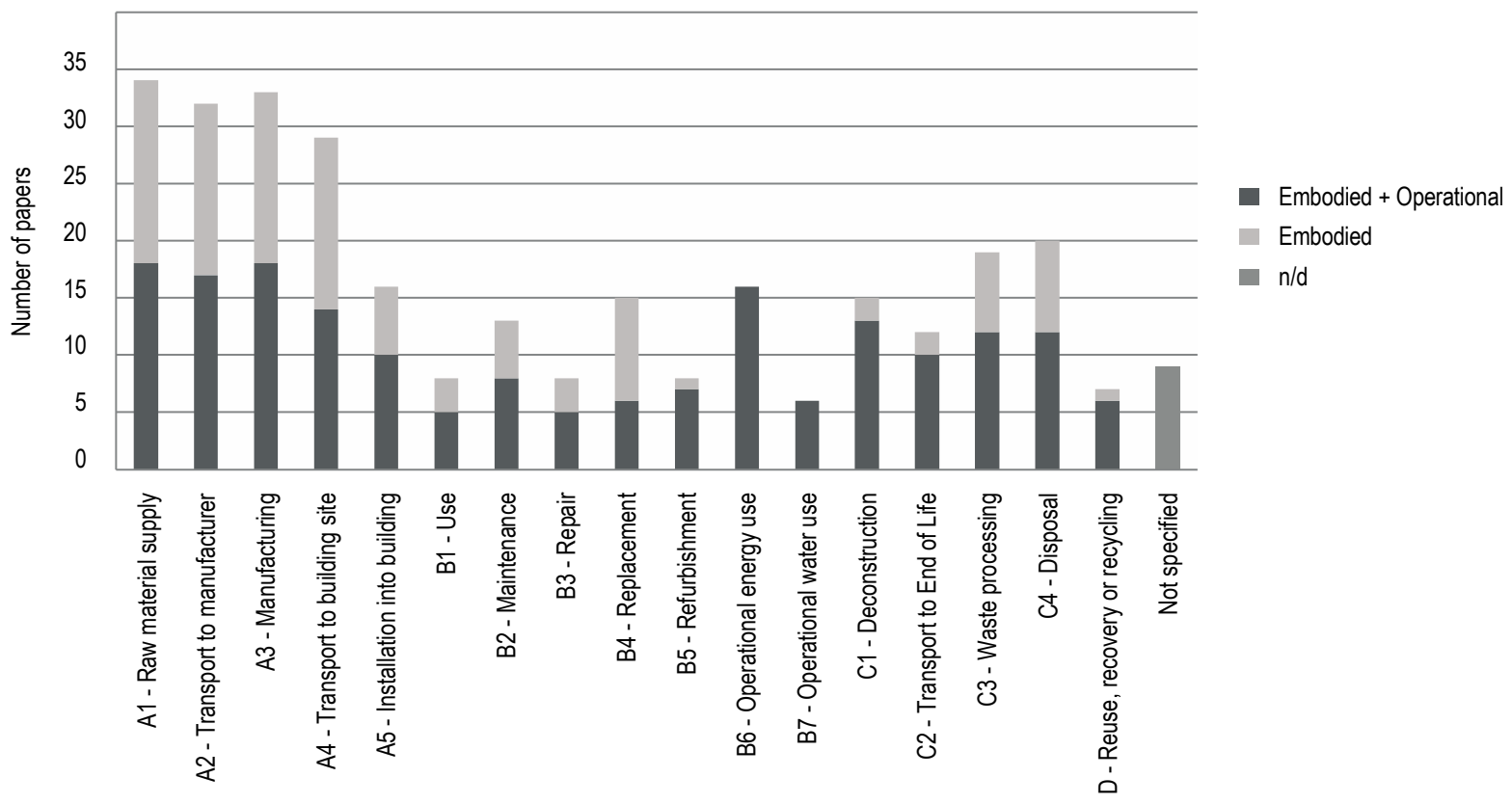

Figure 12. The life cycle stages assessed.
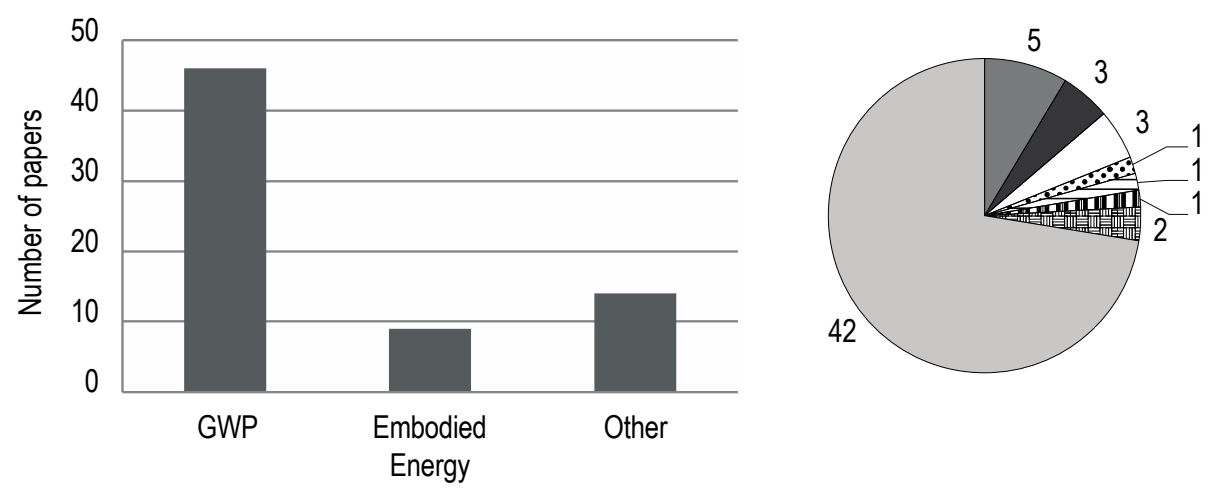

TRACl

$\square \mathrm{CML}$

$\square$ IPCC

8: BRE

Е MMG

III RECIPE

體 Impact 2002

No data

Figure 13. The environmental emission categories assessed, and the characterization methodology used.

\section{Discussion}

\subsection{Technical Issues}

During the review of the identified studies, we observed that each process of integration of LCA and BIM was unique. However, it was possible to define some common integration approaches. The prevailing use of Excel as the LCA calculation tool indicates that the specialized LCA tools experience difficulties in processing the data from BIM tools. In general, we can distinguish between approaches in which all the necessary information is incorporated into the BIM model, and approaches in which the information obtained from BIM models is further processed in other applications. Each approach has its strengths and weaknesses. The first approach exhibits the strength that everything is stored in one model; therefore, no information is lost. On the other hand, this means that the models are complex and rigid, and that better hardware is needed to process the amount of data. The combination of various tools bares a higher risk of information loss during the integration process. Additionally, the information must transfer in such a way that the semantics and ontology of the data are preserved. This task is very demanding because it requires support in the standardization. The IFC 
format should offer an adequate framework for exchanging information, but at this point, software developers are also providing their own solutions that are applicable only within the range of their product palette [18].

Currently, the exchange of data between BIM and LCA is mostly done manually. The information collected in the BoQ is then used in a separate tool, wherein the LCA is performed. This approach is very time-consuming, with the possibility of errors [66]. The additional expenditure of the normal process is not economically bearable, especially if multiple design options have to be compared [36]. A higher degree of automatization of the information exchange between BIM and LCA is expected in the future. The automatization of the integration process is still at an early stage, and can be achieved by the use of a specially developed plug-in. The plug-ins have certain limitations, regarding the availability of data from the materials, little possibility of modification, etc. [46,49]. There are also some studies in which the authors developed complex scripts to integrate the data within the BIM model, or to establish an automatic information exchange between different tools. The developed script could be further used to improve the existing plug-ins or integration approaches. The problem of interoperation between BIM and other tools is also a pressing concern in the case of the energy demand calculation [67].

The most frequently adopted tools for BIM and LCA analyses were identified. These tools indicate the current state-of-the-art of LCA practice, and help in identifying the integration process that should be enhanced.

\subsection{Informational Issues}

A major challenge is determining the relevant inputs that have to be placed in the BIM model. Generally, the BIM model should provide data regarding the quality and quantity of materials, but additional information is needed to conduct an LCA analysis. The studies of Santos et al. and Cavalliere et al. [39,54] provide a comprehensive overview of this topic. Another major challenge is how to connect these data to BIM. Some researchers have proposed a direct integration into the BIM model, while other studies tried to establish a link to external sources of information. If external sources of information are used, then they should conform to the ontology and semantics of the implemented BIM tool. In many cases, external applications were used to establish this connection (e.g., MySQL), which requires additional effort and a certain degree of programming knowledge. We have identified that there is a common need for technical, organizational and semantical interoperability between BIM and LCA.

The quality of the data also depends on the design stage of the projects. During the development stage of projects, the materials and processes used are becoming more determined; therefore, LCA analysis can be increasingly precise [68]. The maturity of the BIM modes can be expressed via the LOD. However, the relation between the LCA analysis and the LOD level of the model should be regulated [7]. In this case, the scopes and goal of the study would directly indicate what LOD is needed for the BIM model. Generally, it was emphasized in numerous studies that the integration between BIM and LCA should be established at an early stage, where changes in the design are still possible. In other words, an LCA should be used to support the development of the design, and not to document the results of the design.

The choice of the database for the LCA calculation should be aligned with the scope of the study, as well as the design stages. During the development of the project databases, different data accuracies, corresponding to the design stages, should be used, as proposed in the study of Cavalliere et al. [29]. However, not all regions have developed databases in this way. The approach suggested in the study can therefore be used for the development of databases for different design stages of the project. It is also important to emphasize that a common approach to the aggregation of data should be established, so the databases can be developed according to this approach. It is also possible that the established systems of data aggregation (e.g., Uniclass, Unifromat, etc.) could be used for this purpose. Another issue observed is that the databases mostly originate, and contain data, from developed 
countries [37]. This is not directly connected to the integration process of BIM and LCA, but the emerging countries are those where much construction work is performed, and the development of accurate databases could help in realistically assessing the associated environmental impacts.

\subsection{Functional Requirement for the LCA}

The LCA methodology strongly influences what information must be integrated into the BIM tool. Some authors identify these as the 6D of BIM [69]. It is crucial to identify the goal and scope of the study. The identification of the scope of the study revealed that there is great variation in these fields. A common LCA methodology for buildings (as will be proposed by IEA EBC Annex 72) could help to solve this issue. If the scope of the study follows some established standards, then it will be easier to identify the inputs needed for the LCA. Additionally, the functional units should follow established standards, in order to avoid a misunderstanding and misinterpretation of the results. The functional unit should provide information regarding what is assessed, its quantity, the period of assessment, and how well it is assessed. BIM tools should enable the structuring of the data so that it conforms to the functional unit. This issue was not addressed or observed in any of the reviewed cases, and opens a new area of investigation.

\subsection{Organizational Issues}

The challenges regarding the integration and automation of the link between BIM and LCA (as presented in Figure 5) are issues strongly connected to the organizational aspects and the standardization of workflows. While customized approaches to linking BIM and LCA can be created on an individual basis, the wide application and automation of LCA in BIM-based processes requires clear industry standards. Standards are required for both LCA and BIM (models), regarding, among other things, ontologies and data structures, as well as the level of information (to be expected/delivered) at a certain design stage. A variety of standardization activities exists, which are related to these topics; see, e.g., the works of CEN/TC 442, or ISO/TC 184/SC 4 and ISO/TC 59/SC 13. However, implementation in everyday industry practice remains a challenge, as recently shown by an international survey among building design professionals [70].

\section{Conclusions}

The concluded SLR included 60 academic papers focusing on the integration of BIM and LCA. The SLR shows the increasing use of BIM, because of its potential to store information required for the environmental assessment of buildings, suggesting it should therefore not be overlooked. The results show that the BIM model, containing information regarding the quantities of materials employed in the building, in $60 \%$ of the cases ( 22 out of 60 papers) is imported manually or semiautomatically into the LCA tool. However, in 17\% (10 papers), the authors showed the possibility of importing the model automatically, making significant progress in the interaction between BIM and LCA tools. This automatization simplifies the assessment of the embodied impacts. Furthermore, $23 \%$ of the studies did not contain data about the importing process, or presented no case study. The analysis of the results found criticisms concerning the building components included in the system boundaries. As considered in $40 \%$ of the cases (24 papers), external walls are the components that are most often included in the system boundaries. Moreover, the system boundaries were mostly limited to the production stage (A1-A3) of the components. This stage was considered in almost $72 \%$ (43 papers) of the cases. On the other hand, the BIM has been shown to be less effective for operational energy evaluation. In only $43 \%$ ( 26 papers) of the cases was the model used for the assessment of the environmental impacts of the operational energy.

Although we have identified many different approaches to integrating BIM and LCA, this process is still at an early stage. Our findings reveal that the major issues of the integration process are (1) creating a synchronized LCA methodology that enables a clear identification of the inputs needed, (2) developing information databases that ontologically and semantically conform to the BIM environment, and that 
also correspond to the desired design phase of the project, and (3) creating a flawless and automated exchange of information between BIM and LCA tools, regardless of whether they are embedded in the BIM environment or used as separate files.

A more reliable integration of BIM and LCA would foster the optimization of the environmental performance of buildings during the design process, and thereby improve the future building stock quality. An optimized integration of BIM and LCA, where the users have control, and an overview, of the entire range of processes and material flows during the entire life cycle of the building, will likely lead to an improved design process, as well as generating replicable and trustworthy LCA results.

Author Contributions: Conceptualization, T.P.O., M.R. and A.P.; methodology, T.P.O., M.R., E.H. and A.P.; formal analysis, T.P.O.; investigation, T.P.O.; writing—original draft preparation, T.P.O.; writing-review and editing, A.P., M.R. and E.H.; visualization, T.P.O., E.H.; supervision, A.P. and E.H. All authors have read and agreed to the published version of the manuscript.

Funding: The Slovenian contribution is financially supported by the Slovenian Research Agency (Young Researcher Funding 38191). The Austrian contribution is financially supported by the Austrian Ministry for Transport, Innovation and Technology (BMVIT) via IEA Research Cooperation via the Austrian Research Promotion Agency (FFG) Grant \#864142. Martin Röck is the recipient of a DOC Fellowship of the Austrian Academy of Sciences. The Open Access is funded by the Graz University of Technology.

Acknowledgments: The work was performed as a part of the IEA EBC Annex 72 (http://annex72.iea-ebc.org) Subtask 2 activity. The authors thank the experts who provided useful input and sources of information. The authors would like to thank Theres Reisinger and Dominik Maierhofer for providing help with data illustration.

Conflicts of Interest: The authors declare no conflicts of interest.

\section{References}

1. UNEP Sustainable Buildings|UNEP-UN Environment Programme. Available online: https://www. unenvironment.org/explore-topics/resource-efficiency/what-we-do/cities/sustainable-buildings (accessed on 10 April 2020).

2. Ramesh, T.; Prakash, R.; Shukla, K. Life cycle energy analysis of buildings: An overview. Energy Build. 2010, 42, 1592-1600. [CrossRef]

3. Cabeza, L.F.; Barreneche, C.; Miró, L.; Morera, J.M.; Bartolí, E.; Fernandez, A.I. Low carbon and low embodied energy materials in buildings: A review. Renew. Sustain. Energy Rev. 2013, 23, 536-542. [CrossRef]

4. Buyle, M.; Braet, J.; Audenaert, A. Life cycle assessment in the construction sector: A review. Renew. Sustain. Energy Rev. 2013, 26, 379-388. [CrossRef]

5. Röck, M.; Ruschi Mendes Saade, M.; Balouktsi, M.; Rasmussen, F.N.; Birgisdóttir, H.; Frischknecht, R.; Habert, G.; Lützkendorf, T.; Passer, A. Embodied GHG emissions of buildings-The hidden challenge for effective climate change mitigation. Appl. Energy 2020, 258, 114107. [CrossRef]

6. Häfliger, I.-F.; John, V.; Passer, A.; Lasvaux, S.; Hoxha, E.; Saade, M.R.M.; Habert, G. Buildings environmental impacts' sensitivity related to LCA modelling choices of construction materials. J. Clean. Prod. 2017, 156, 805-816. [CrossRef]

7. Soust-Verdaguer, B.; Llatas, C.; García-Martínez, A. Critical review of bim-Based LCA method to buildings. Energy Build. 2017, 136, 110-120. [CrossRef]

8. BIM Dictionary. Available online: https://bimdictionary.com/terms/search (accessed on 1 May 2020).

9. Volk, R.; Stengel, J.; Schultmann, F. Building Information Modeling (BIM) for existing buildings-Literature review and future needs. Autom. Constr. 2014, 38, 109-127. [CrossRef]

10. Antón, L.Á.; Diaz, J. Integration of Life Cycle Assessment in a BIM Environment. Procedia Eng. 2014, 85, 26-32. [CrossRef]

11. Nizam, R.S.; Zhang, C.; Tian, L. A BIM based tool for assessing embodied energy for buildings. Energy Build. 2018, 170, 1-14. [CrossRef]

12. Wastiels, L.; Decuypere, R. Identification and comparison of LCA-BIM integration strategies. In Proceedings of the IOP Conference Series Earth and Environmental Science, Graz, Austria, 11-14 September 2019; Volume 323. [CrossRef] 
13. Wohlin, C. Guidelines for snowballing in systematic literature studies and a replication in software engineering. In Proceedings of the 18th International Conference on Evaluation and Assessment in Software Engineering (EASE '14), London, UK, 13-14 May 2014. [CrossRef]

14. Saade, M.R.M.; Gomes, V.; da Silva, M.G.; Ugaya, C.M.L.; Lasvaux, S.; Passer, A.; Habert, G. Investigating transparency regarding ecoinvent users' system model choices. Int. J. Life Cycle Assess. 2018, 24, 1-5. [CrossRef]

15. Saade, M.R.M.; Passer, A.; Mittermayr, F. (Sprayed) concrete production in life cycle assessments: A systematic literature review. Int. J. Life Cycle Assess. 2020, 25, 188-207. [CrossRef]

16. Liu, S.; Meng, X.; Tam, C.M. Building information modeling based building design optimization for sustainability. Energy Build. 2015, 105, 139-153. [CrossRef]

17. Alireza, A.F.F.; Rashidi, T.H.; Akbarnezhad, A.; Waller, S.T. BIM-Enabled sustainability assessment of material supply decisions. Eng. Constr. Arch. Manag. 2017, 24, 668-695. [CrossRef]

18. Jrade, A.; Jalaei, F. Integrating building information modelling with sustainability to design building projects at the conceptual stage. Build. Simul. 2013, 6, 429-444. [CrossRef]

19. Basbagill, J.; Flager, F.; Lepech, M.; Fischer, M. Application of life-Cycle assessment to early stage building design for reduced embodied environmental impacts. Build. Environ. 2013, 60, 81-92. [CrossRef]

20. Georges, L.; Haase, M.; Wiberg, A.H.; Kristjansdottír, T.; Risholt, B. Life cycle emissions analysis of two nZEB concepts. Build. Res. Inf. 2014, 43, 82-93. [CrossRef]

21. Yang, X.; Hu, M.; Wu, J.; Zhao, B. Building-Information-Modeling enabled life cycle assessment, a case study on carbon footprint accounting for a residential building in China. J. Clean. Prod. 2018, 183, 729-743. [CrossRef]

22. Eleftheriadis, S.; Duffour, P.; Mumovic, D. BIM-Embedded life cycle carbon assessment of RC buildings using optimised structural design alternatives. Energy Build. 2018, 173, 587-600. [CrossRef]

23. Peng, C.; Wu, X. Case Study of Carbon Emissions from a Building's Life Cycle Based on BIM and Ecotect. Adv. Mater. Sci. Eng. 2015, 2015, 1-15. [CrossRef]

24. Peng, C. Calculation of a building's life cycle carbon emissions based on Ecotect and building information modeling. J. Clean. Prod. 2016, 112, 453-465. [CrossRef]

25. Oh, M.S.; Na, S. Building information modelling (BIM) based $\mathrm{CO}_{2}$ emissions assessment in the early design stage. Int. J. Civ. Eng. Technol. 2017, 8, 1411-1425.

26. Wang, J.; Wu, H.; Duan, H.; Zillante, G.; Zuo, J.; Yuan, H. Combining life cycle assessment and Building Information Modelling to account for carbon emission of building demolition waste: A case study. J. Clean. Prod. 2018, 172, 3154-3166. [CrossRef]

27. Panteli, C.; Kylili, A.; Stasiuliene, L.; Seduikyte, L.; Fokaides, P.A. A framework for building overhang design using Building Information Modeling and Life Cycle Assessment. J. Build. Eng. 2018, 20, 248-255. [CrossRef]

28. Rezaei, F.; Bulle, C.; Lesage, P. Integrating building information modeling and life cycle assessment in the early and detailed building design stages. Build. Environ. 2019, 153, 158-167. [CrossRef]

29. Cavalliere, C.; Habert, G.; Dell'Osso, G.R.; Hollberg, A. Continuous BIM-based assessment of embodied environmental impacts throughout the design process. J. Clean. Prod. 2019, 211, 941-952. [CrossRef]

30. Feng, H.; Liyanage, D.R.; Karunathilake, H.; Sadiq, R.; Hewage, K. BIM-Based life cycle environmental performance assessment of single-Family houses: Renovation and reconstruction strategies for aging building stock in British Columbia. J. Clean. Prod. 2020, 250, 119543. [CrossRef]

31. Lu, K.; Jiang, X.; Tam, V.W.; Li, M.; Wang, H.; Xia, B.; Chen, Q. Development of a Carbon Emissions Analysis Framework Using Building Information Modeling and Life Cycle Assessment for the Construction of Hospital Projects. Sustainability 2019, 11, 6274. [CrossRef]

32. Sartori, T.; Calmon, J.L. Analysis of the impacts of retrofit actions on the life cycle energy consumption of typical neighbourhood dwellings. J. Build. Eng. 2019, 21, 158-172. [CrossRef]

33. Soust-Verdaguer, B.; Llatas, C.; García-Martínez, A.; De Cózar, J.C.G. BIM-Based LCA Method to Analyze Envelope Alternatives of Single-Family Houses: Case Study in Uruguay. J. Arch. Eng. 2018, 24, 05018002. [CrossRef]

34. Shafiq, N.; Nurrudin, M.F.; Gardezi, S.S.S.; Bin Kamaruzzaman, A. Carbon footprint assessment of a typical low rise office building in Malaysia using building information modelling (BIM). Int. J. Sustain. Build. Technol. Urban Dev. 2015, 6, 1-16. [CrossRef] 
35. Ajayi, S.; Oyedele, L.; Ceranic, B.; Gallanagh, M.; Kadiri, K.O. Life cycle environmental performance of material specification: A BIM-enhanced comparative assessment. Int. J. Sustain. Build. Technol. Urban Dev. 2015, 6, 14-24. [CrossRef]

36. Abanda, F.; Oti, A.; Tah, J. Integrating BIM and new rules of measurement for embodied energy and $\mathrm{CO}_{2}$ assessment. J. Build. Eng. 2017, 12, 288-305. [CrossRef]

37. Kumanayake, R.; Luo, H. Development of an Automated Tool for Buildings' Sustainability Assessment in Early Design Stage. Procedia Eng. 2017, 196, 903-910. [CrossRef]

38. Bueno, C.; Pereira, L.M.; Fabricio, M.M. Life cycle assessment and environmental-based choices at the early design stages: An application using building information modelling. Arch. Eng. Des. Manag. 2018, 14, 332-346. [CrossRef]

39. Cavalliere, C.; Dell'Osso, G.R.; Pierucci, A.; Iannone, F. Life cycle assessment data structure for building information modelling. J. Clean. Prod. 2018, 199, 193-204. [CrossRef]

40. Hollberg, A.; Genova, G.; Habert, G. Evaluation of BIM-based LCA results for building design. Autom. Constr. 2020, 109, 102972. [CrossRef]

41. Crippa, J.; Boeing, L.C.; Caparelli, A.P.A.; da do de Costa, M.R.M.M.; Scheer, S.; Araujo, A.M.F.; Bem, D. A BIM-LCA integration technique to embodied carbon estimation applied on wall systems in Brazil. Built Environ. Proj. Asset Manag. 2018, 8, 491-503. [CrossRef]

42. Jalaei, F.; Jrade, A. An Automated BIM Model to Conceptually Design, Analyze, Simulate, and Assess Sustainable Building Projects. J. Constr. Eng. 2014, 2014, 1-21. [CrossRef]

43. Shadram, F.; Johansson, T.; Lu, W.; Schade, J.; Olofsson, T. An integrated BIM-based framework for minimizing embodied energy during building design. Energy Build. 2016, 128, 592-604. [CrossRef]

44. Marzouk, M.; Azab, S.; Metawie, M. Framework for Sustainable Low-Income Housing Projects using Building Information Modeling. J. Environ. Inform. 2016, 28, 25-38. [CrossRef]

45. Jiang, S.; Lei, W. The Application of BIM in Green Building Energy Saving: Take Helsinki Music Center as an Example. Adv. Mater. Res. 2014, 935, 3-7. [CrossRef]

46. Najjar, M.K.; Figueiredo, K.; Palumbo, M.; Haddad, A.N. Integration of BIM and LCA: Evaluating the environmental impacts of building materials at an early stage of designing a typical office building. J. Build. Eng. 2017, 14, 115-126. [CrossRef]

47. Najjar, M.K.; Figueiredo, K.; Hammad, A.W.; Haddad, A.N. Integrated optimization with building information modeling and life cycle assessment for generating energy efficient buildings. Appl. Energy 2019, 250, 1366-1382. [CrossRef]

48. Raposo, C.; Rodrigues, F.; Rodrigues, H. BIM-based LCA assessment of seismic strengthening solutions for reinforced concrete precast industrial buildings. Innov. Infrastruct. Solut. 2019, 4, 1-10. [CrossRef]

49. Bueno, C.; Fabricio, M.M. Comparative analysis between a complete LCA study and results from a BIM-LCA plug-in. Autom. Constr. 2018, 90, 188-200. [CrossRef]

50. Hollberg, A.; Ruth, J. LCA in architectural design-A parametric approach. Int. J. Life Cycle Assess. 2016, 21, 943-960. [CrossRef]

51. Lee, S.-K.; Kim, K.; Yu, J.-H. BIM and ontology-based approach for building cost estimation. Autom. Constr. 2014, 41, 96-105. [CrossRef]

52. Jalaei, F.; Zoghi, M.; Khoshand, A. Life cycle environmental impact assessment to manage and optimize construction waste using Building Information Modeling (BIM). Int. J. Constr. Manag. 2019, 1-18. [CrossRef]

53. Kulahcioglu, T.; Dang, J.; Toklu, C. A 3D analyzer for BIM-enabled Life Cycle Assessment of the whole process of construction. HVAC R Res. 2012, 18, 283-293. [CrossRef]

54. Santos, R.; Costa, A.A.; Silvestre, J.D.; Pyl, L. Integration of LCA and LCC analysis within a BIM-Based environment. Autom. Constr. 2019, 103, 127-149. [CrossRef]

55. Santos, R.; Costa, A.A.; Silvestre, J.D.; Vandenbergh, T.; Pyl, L. BIM-based life cycle assessment and life cycle costing of an office building in Western Europe. Build. Environ. 2020, 169, 106568. [CrossRef]

56. Russell-Smith, S.; Lepech, M.D. Dynamic Life Cycle Assessment of Building Design and Retrofit Processes. Comput. Civ. Eng. 2011, 760-767. [CrossRef]

57. European Committee for Standardization En 15978. Sustainable Construction Work-Assessment Environmental Performance Building_Calculating Method 2011; CEN: Brussels, Belgium, 2011. 
58. Lee, S.; Tae, S.; Roh, S.; Kim, T. Green Template for Life Cycle Assessment of Buildings Based on Building Information Modeling: Focus on Embodied Environmental Impact. Sustainability 2015, 7, 16498-16512. [CrossRef]

59. Caplehorn, P.; Caplehorn, P. RIBA Plan of Work 2020 Overview. Available online: https://www.architecture.com/-/media/GatherContent/Test-resources-page/Additional-Documents/ 2020RIBAPlanofWorktemplatepdf.pdf (accessed on 17 June 2020).

60. Röck, M.; Hollberg, A.; Habert, G.; Passer, A. LCA and BIM: Visualization of environmental potentials in building construction at early design stages. Build. Environ. 2018, 140, 153-161. [CrossRef]

61. Martínez-Rocamora, A.; Solís-Guzmán, J.; Marrero, M. LCA databases focused on construction materials: A review. Renew. Sustain. Energy Rev. 2016, 58, 565-573. [CrossRef]

62. Gantner, J.; Lenz, K.; Horn, R.; Von Both, P.; Ebertshäuser, S. Ökobau.dat 3.0-Quo Vadis? Buildings 2018, 8, 129. [CrossRef]

63. IEA EBC Iea Ebc Annex 72. Available online: http://www.iea-ebc.org/projects/ongoing-projects/ebc-annex-72/ (accessed on 1 May 2020).

64. Bribian, I.Z.; Uson, J.A.A.; Scarpellini, S. Life cycle assessment in buildings: State-of-the-art and simplified LCA methodology as a complement for building certification. Build. Environ. 2009, 44, 2510-2520. [CrossRef]

65. Buyle, M.; Braet, J.; Audenaert, A. Life Cycle Assessment of an Apartment Building: Comparison of an Attributional and Consequential Approach. Energy Procedia 2014, 62, 132-140. [CrossRef]

66. Shadram, F.; Mukkavaara, J. An integrated BIM-Based framework for the optimization of the trade-off between embodied and operational energy. Energy Build. 2018, 158, 1189-1205. [CrossRef]

67. Gao, H.; Koch, C.; Wu, Y. Building information modelling based building energy modelling: A review. Appl. Energy 2019, 238, 320-343. [CrossRef]

68. Shin, Y.-S.; Cho, K. BIM Application to Select Appropriate Design Alternative with Consideration of LCA and LCCA. Math. Probl. Eng. 2015, 2015, 1-14. [CrossRef]

69. Yung, P.; Wang, X. A 6D CAD Model for the Automatic Assessment of Building Sustainability. Int. J. Adv. Robot. Syst. 2014, 11, 131. [CrossRef]

70. Balouktsi, M.; Lützkendorf, T.; Röck, M.; Passer, A.; Reisinger, T.; Frischknecht, R. Survey results on acceptance and use of Life Cycle Assessment among designers in world regions: IEA EBC Annex 72. In Proceedings of the World Sustainable Built Environment Conference, Gothenburg, Sweden, 9-11 June 2020, in press. 